\title{
CONGENITAL PULMONARY ATRESIA WITH CEREBRAL THROMBOSIS AND HEMIPLEGIA
}

\author{
BY
}

ALASTAIR HUNTER AND JOHN M. LIPSCOMB

From the Cardiac Department of the London Hospital and the Bernhard Baron Institute of Pathology

Received July 7, 1942

In view of the recent communication of Corner and Bruce Perry (1942) the following case is of special interest.

A girl, aged 19 (Fig. 1), was first seen on February 21, 1942, when she was admitted to the London Hospital for dental extractions. Since the age of 2 she had been under observation for " heart trouble" with blueness and swollen fingers. Her activities had always been limited by shortness of breath, although for the last three years she had been capable of light work in the home. There had been no faints or cerebral attacks, and there was no history of congenital heart disease in parents or siblings.

She was a tall and well-developed girl with purple cyanosis; this was general, but most striking on the cheeks and lips, as well as in the fingers and toes, which were grossly clubbed. The pulse was regular and of good volume. The apex beat was palpable in the fifth space in the mid-clavicular line, and there were no thrills. Normal heart sounds were heard in all areas, and there was a diffuse systolic murmur of only moderate intensity, maximal in the pulmonary area and below it. The blood pressure was 120/80. There were scattered rhonchi over both lungs and slight lumbar œdema, but no other signs of heart failure.

Radiological examination showed much enlargement of the cardiac outline to the left, probably of the right ventricle, as it was of a sabot shape. There was a deep concavity in the pulmonary artery region and only slight hilar shadows (Fig. 2). The blood count showed: red cells, 7,160,000; white cells, 6120; hæmoglobin, 136 per cent (Sahli); and hæmatocrit readings, 65 and 75 . A diagnosis of congenital pulmonary atresia was made by Dr. William Evans who noted the limited cardiac signs despite the great cyanosis.

Dental extractions were performed uneventfully under gas and oxygen anæsthesia. Venesection on three occasions had no effect upon the patient's condition or blood picture. She was discharged on March 14. On April 2 she was readmitted after an epileptiform fit preceded by difficulty in speech and loss of power in the left side of the face and left arm. The general appearance was unaltered unless the cyanosis was deeper, and there was now orthopnœa. 
The temperature was 102 and the pulse rate 88 . The cardiac signs were unchanged. There was drowsiness, slurring of speech, and neck rigidity. Slight left facial weakness of upper motor neurone type was combined with flaccid weakness of the left arm with absent tendon reflexes. These were the only abnormal signs in the nervous system. After admission the patient had several minor, and one major, epileptiform attacks. Lumbar puncture showed a yellow C.S.F. under pressure of $230 \mathrm{~mm}$. It contained red cells $(800$ per

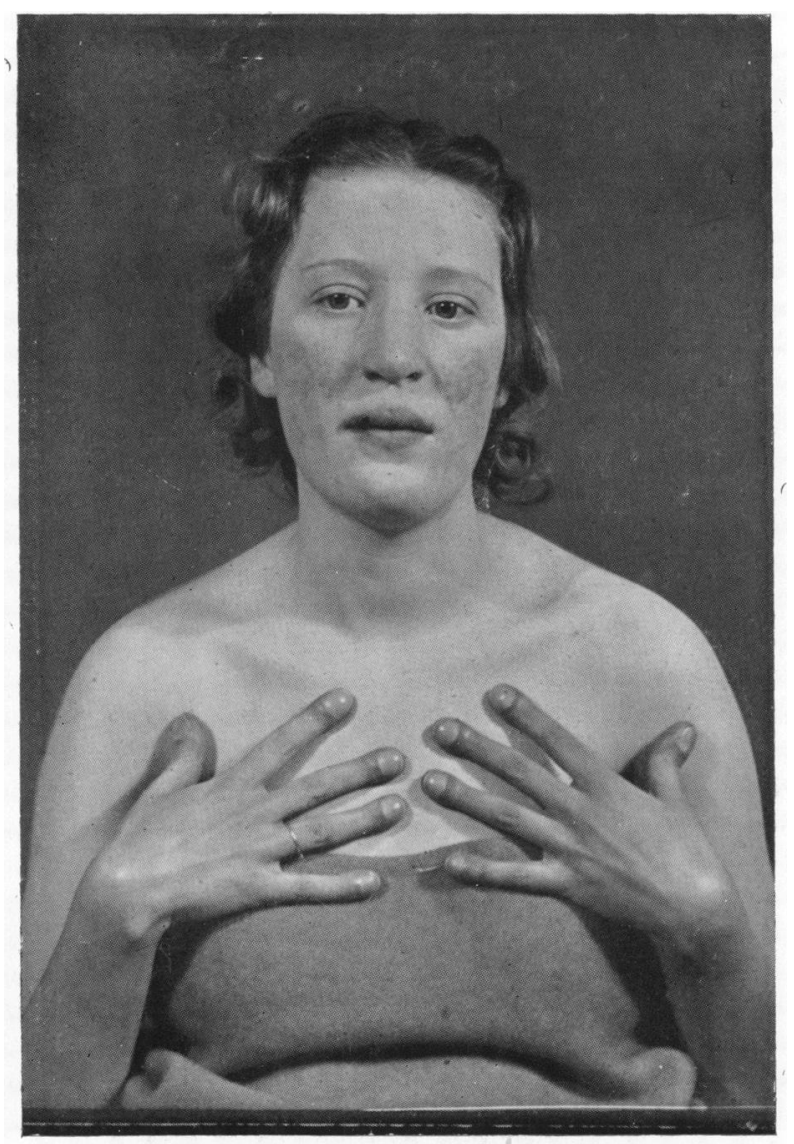

Fig. 1.-Photograph of patient showing cyanosis and clubbing of fingers.

c. $\mathrm{mm}$.), no excess of white cells, and protein $30 \mathrm{mg}$. per 100 c.c. In subsequent days she improved, the nervous symptoms and signs disappeared, and she was fit to get up. But one month after admission she developed a sudden pain under the left costal margin with fever, attributed after necropsy to a paradoxical splenic infarct. The spleen was never felt, but great odema of both lower limbs with tenderness in the groins indicated spreading iliac thrombosis. The general condition deteriorated and she died in coma on May 13, 1942, eight days after the final thrombotic illness. 


\section{Summary of Necropsy (Dr. W. W. WoOds)}

Heart failure. Thrombosis in cerebral and pelvic veins. Congenital atresia of orifice of pulmonary artery. Patency of interventricular septum. Enlargement of bronchial arteries.

Small pulmonary artery $(1 \cdot 3 \mathrm{~cm}$. long; $1 \cdot 3 \mathrm{~cm}$. circumf.) starting from a blind end at upper margin of right ventricle and dividing into very thin-walled right and left pulmonary arteries (each $1.8 \mathrm{~cm}$. circumf., with wall less than $0.05 \mathrm{~cm}$. thick), which go into hila of lungs. No trace of conus arteriosus or pulmonary valves on inner surface of right ventricle (Fig. 3). Patency $(3 \mathrm{~cm}$. diam.) of upper end of interventri-

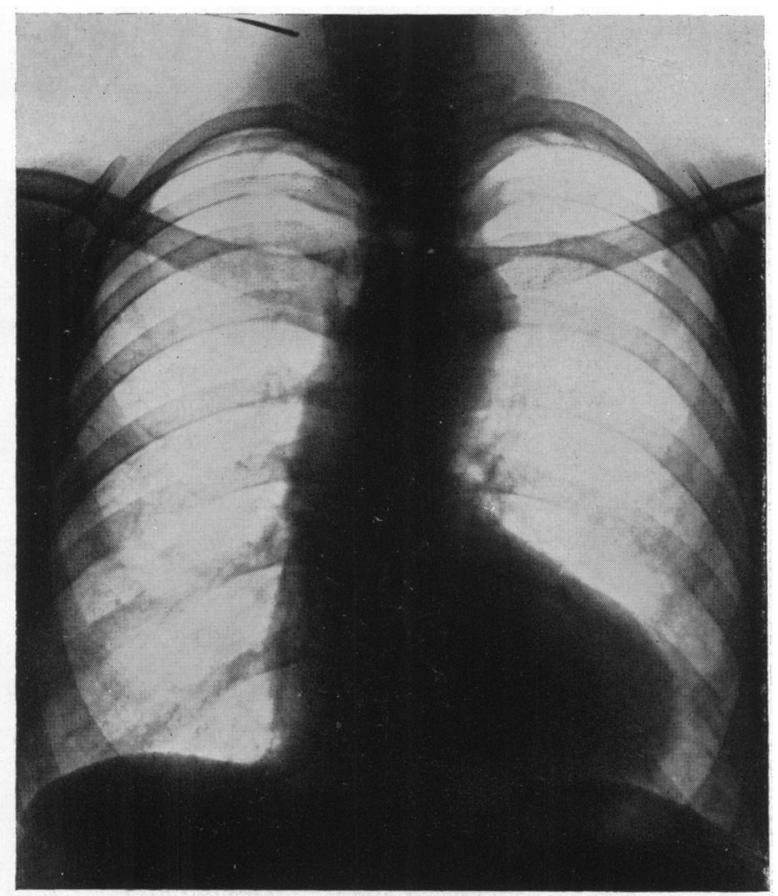

FIG. 2.-Teleradiogram, showing Cour en Sabot and deep pulmonary bay with small hilar vessels.

cular septum immediately below anterior cusp of aortic valve and not involving pars membranacea septi. Greatly enlarged, very thin, almost transparent, right bronchial artery $(2.5 \mathrm{~cm}$. circumf.) arising (orifice $1 \mathrm{~cm}$. diam.) from the aorta immediately beneath the level of the closed ductus arteriosus (Fig. 4), its three branches going to the three lobes of right lung. Upper left bronchial artery $(0.5 \mathrm{~cm}$. circumf.) arising from aorta, $0.7 \mathrm{~cm}$. below the right, by an incongruously wide orifice $(1 \mathrm{~cm}$. diam.) and entering hilum of left lung. Lower left bronchial artery $(1.2 \mathrm{~cm}$. circumf.), with thin, almost transparent wall, arising (orifice $0.5 \mathrm{~cm}$. diam.) from aorta $0.7 \mathrm{~cm}$. below upper, and entering lower part of hilum of left lung. Foramen ovale and ductus arteriosus closed. Great hypertrophy of right ventricle $(2 \mathrm{~cm}$. thick), forming apex of heart. Small left ventricle $(1 \mathrm{~cm}$. thick). Normal pulmonary veins entering left auricle. Aortic orifice $9.5 \mathrm{~cm}$. in circumference. Three abnormally large aortic cusps (width, upper edge, $4 \mathrm{~cm}$.; depth, $2 \mathrm{~cm}$.). Slight fibrous thickening of free margin of tricuspid valve and of free margins of aortic cusps. Large coronary arteries (right $1 \mathrm{~cm}$., anterior descending $1.5 \mathrm{~cm}$. circumf.). Slight atheroma of aorta. No atheroma of 


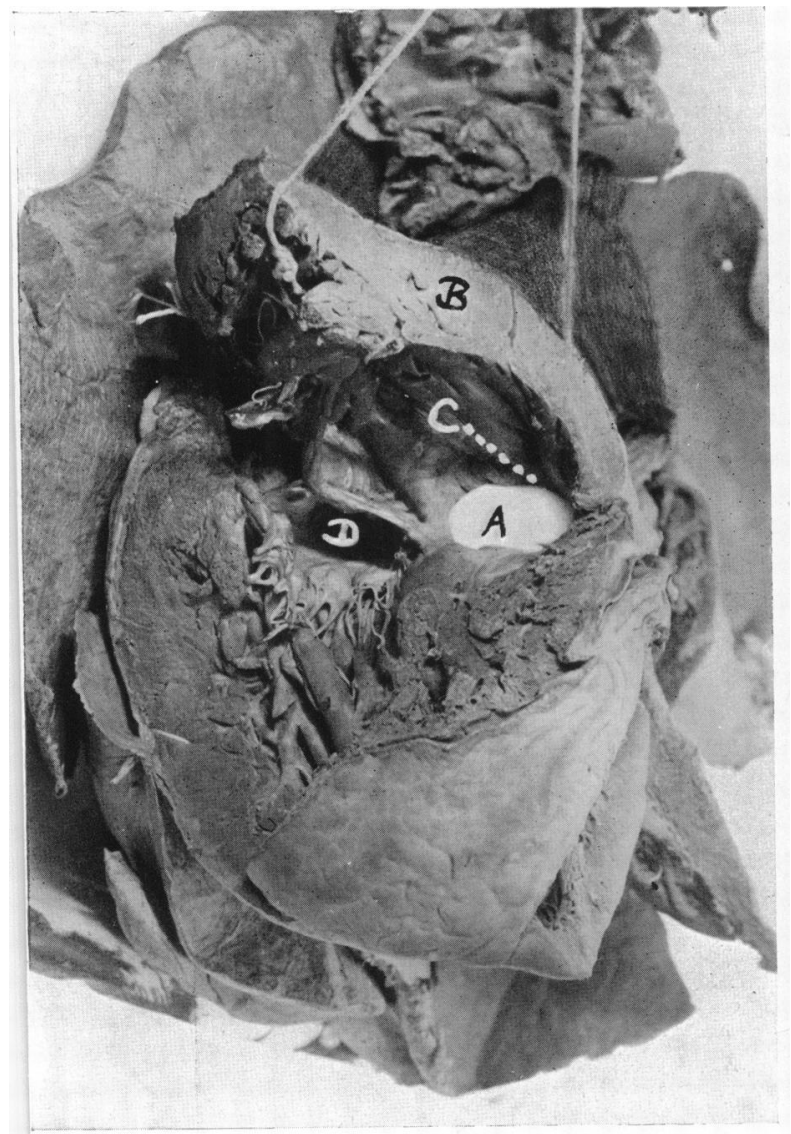

FIG. 3.-Right ventricle opened, showing:

(A) Ventricular septal defect.

(B) Hypertrophied wall of right ventricle.

(C) Site of pulmonary atresia.

(D) Tricuspid valve leading to right auricle.

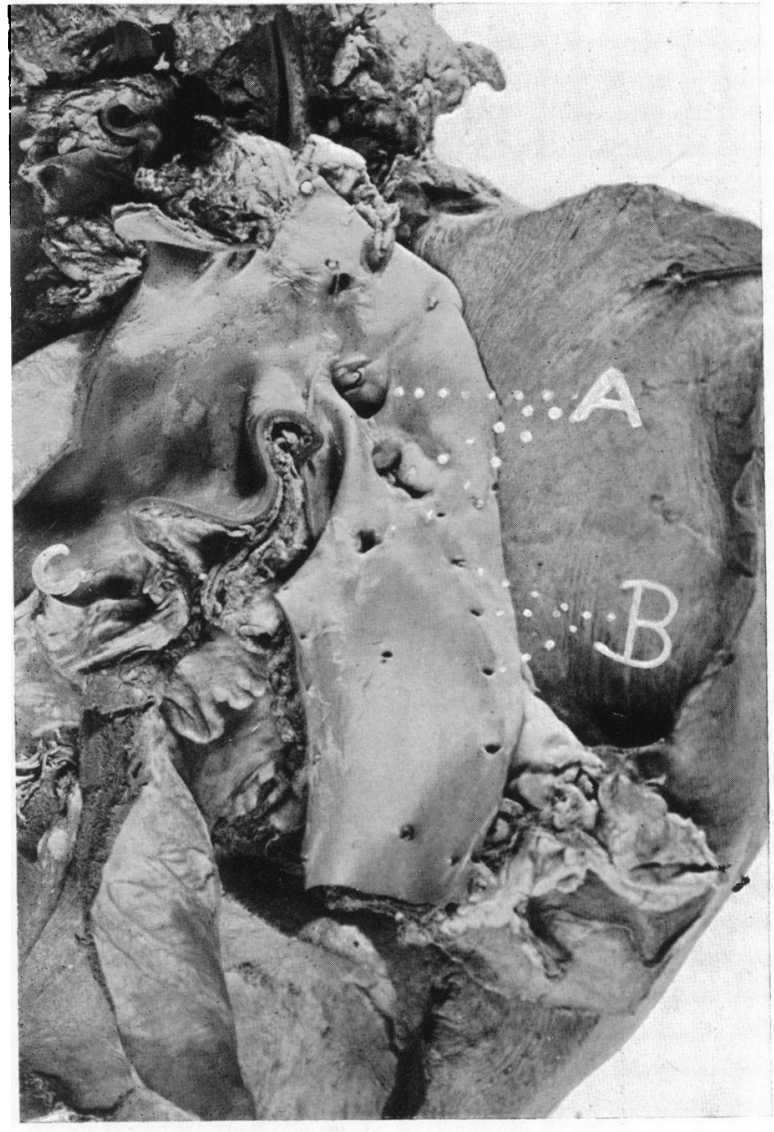

FIG. 4.-Aorta opened, showing:

(A) Dilated orifices of (upper) one right and (lower) two left bronchial arteries, maintaining pulmonary circulation.

(B) Normal intercostal arteries.

(C) Aortic valve.

bronchial arteries. Emphysema and moderate œdema of lungs. Very great dilatation of large left $(1.2 \mathrm{~cm}$. diam.) and right $(1.7 \mathrm{~cm}$. diam.) superior anastomotic vein of Trollard, posterior anastomotic vein of Labbé, and superficial Sylvian vein. These veins on right and a few tributaries of the right vein of Trollard filled with firm ante-mortem thrombus (Fig. 5). Canalized occlusion of termination of left superficial Sylvian vein. Cavernous and circular sinuses unfortunately not carefully examined during removal of pituitary body. No thrombosis nor dilatation of superior longitudinal and lateral sinuses. No petechiæ nor softening in horizontal sections of right cerebrum. Considerably adherent ante-mortem thrombus filling right common iliac vein and upper end of right external iliac. Less adherent ante-mortem thrombus filling left common iliac vein. Non-adherent ante-mortem thrombus filling lower fourth of inferior vena cava. More recent ante-mortem thrombus in femoral veins. Moderate œdema of left leg; slight of right. Recent ante-mortem thrombus in very dilated veins $(0.6 \mathrm{~cm}$. diam.) in myometrium of fundus of uterus, in parts of very conspicuous plexus of veins in each broad ligament, throughout dilated right ovarian vein and in lower end of dilated left ovarian vein. Bicornuate uterus. Softened anæmic infarct $(7 \times 3 \mathrm{~cm}$. $)$ 
in œdematous, congested spleen, presumably due to an embolus from a thrombosed vein having crossed through the patent interventricular septum. Lightly adherent thrombus riding bifurcation of aorta, probably also a crossed embolus. Congestion and nephrosis of large, lipoid-flecked, kidneys. Diffuse congestion of liver, stomach, pancreas, and bladder.

\section{Microscopical Examination}

The brain and portions of kidney and lung were placed in 4 per cent saline formaldehyde. In the time available it was possible only to stain frozen sections by Herxheimer's method and to embed tissue in paraffin by a rapid method, using the exhaust pump, and to stain with hæmatoxylin and eosin, Weigert's iron hæmatoxylin with van Gieson, Weigert's fuchselin with neutral red, and by Lenhossek's method for Nissl bodies.

Brain. A horizontal segment was taken from the right cerebrum, where above the sharp anterior bend of the vein of Trollard a piece of the post-central gyrus is exposed (Fig. 5). The segment included the thrombosed vein, the post-central gyrus, the

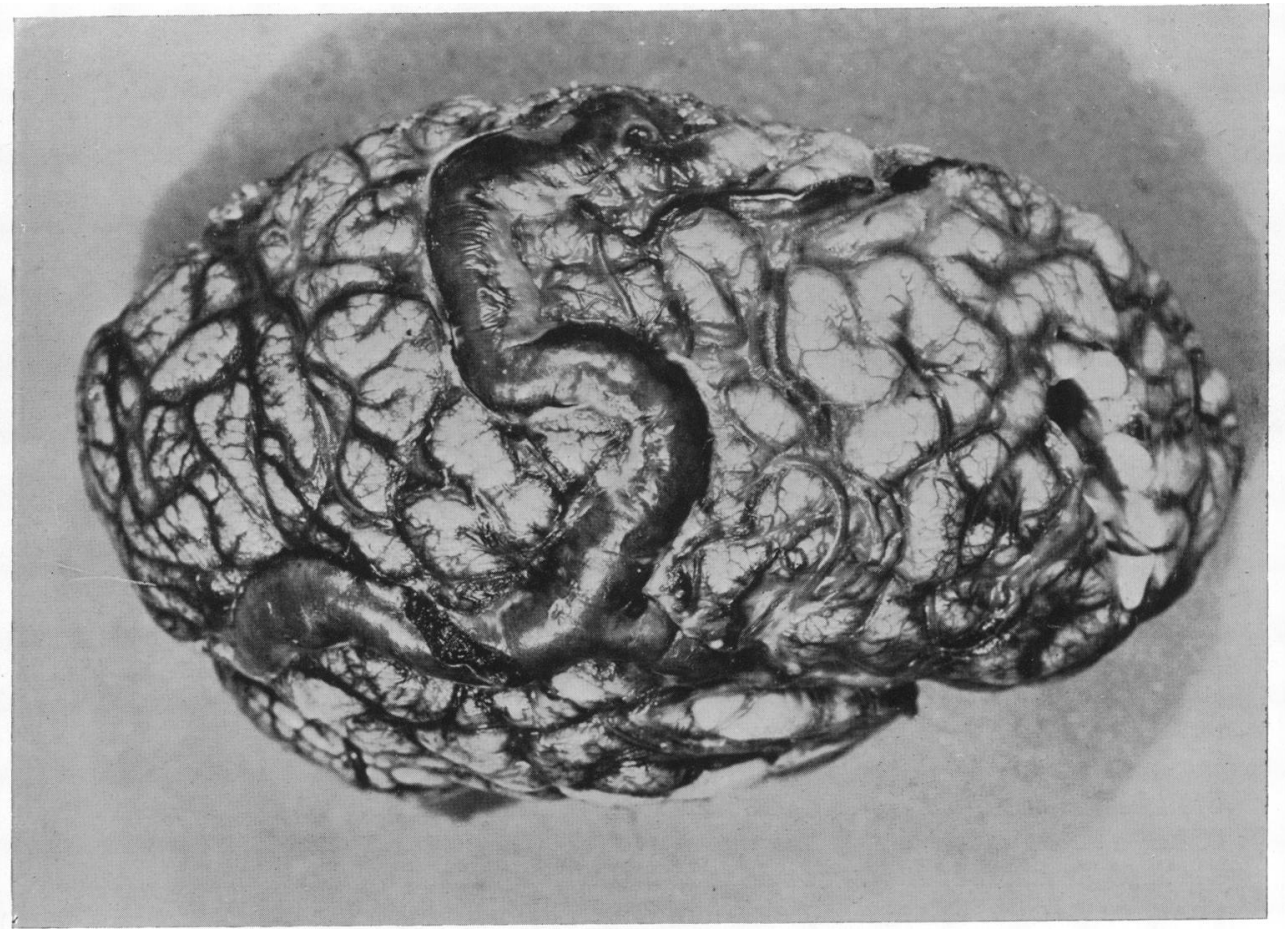

FIG. 5.-Right hemisphere; enlarged, thrombosed superior anastomotic vein of Trollard and posterior anastomotic vein of Labbé, joining superficial Sylvian vein. The anterior end is to the right, and the brain has been tilted so that the anterior and upper parts are more prominent.

inferior post-central sulcus, and the pre-central gyrus near the junction of its upper and middle thirds. Two other segments were taken from the inferior frontal gyrus, 3 and $3.5 \mathrm{~cm}$. from the anterior pole, one for Herxheimer's method and one for rapid paraffin embedding.

The clot in the vein of Trollard is red, with a few small mixed areas. In its outer margin are scattered pigment granule cells, while early organization is shown by capillaries and a few fibrocytes. There is partial thrombosis of a vein deep in the 
inferior post-central sulcus. The pia-arachnoid over the vein of Trollard and extending over the greater part of the summit of the post-central gyrus is greatly infiltrated with free, round endothelial cells; some contain pigment. In a narrow zone immediately above the vein are numerous neutrophil leucocytes. The pia in the inferior post-central sulcus is fibrosed, containing numerous fibrocytes, and is infiltrated chiefly with lymphocytes but also with monocytes, epithelioid cells, and a few neutrophil leucocytes and pigment granule-cells. Where the centre of the convexity of the vein is opposite the post-central gyrus the adjacent cortex, including the layer of small pyramidal cells, is densely infiltrated with rod and other apparently microglial cells. Similar cells extend in decreasing number to the polymorphic layer. In this anterior part of the gyrus, and to a less degree in the posterior, there is an obvious excess of small round, apparently oligodendroglial, cells about neurons, especially in the deeper layers. In the pre-central gyrus there is conspicuously less cellularity but the satellite cells in the deeper layers appear to be in excess of those in the prefrontal section. Even in the post-central gyrus few of the pyramidal cells have lost their shape and in the pre-central gyrus they are well shaped and do not differ from those in the prefrontal region. The nuclei of neurons are central, though the nucleoli are occasionally peripheral. The Nissl bodies are almost always finely granular and indistinct, though larger fused masses are occasionally seen in the periphery of the cytoplasm and most of the Betz cells contain deeply stained rounded masses. In the prefrontal section, however, Nissl bodies show similar changes, so that their condition everywhere is probably due to post-mortem change or rapid fixation and embedding. The conspicuous perivascular, perineuronal, and pericellular spaces of His demonstrate faulty fixation or embedding. There are no hæmorrhages. There are no fat granule-cells in the Herxheimer sections, which do not, however, include the thrombosed vein and the post-central cortex immediately to its side.

Kidneys. Greatly congested; giomeruli, large with considerable proliferative glomerulitis. Three glomerular adhesions were found, and there is early fibrosis and infiltration with lymphocytes and an occasional neutrophil leucocyte round a few glomeruli or about their afferent vessels. In the interstitial tissue a few spindle cells and small groups of foam cells contain lipoid; lipoid is present less often in cells of first convoluted tubules.

Lung, right lower lobe. Congested and emphysematous; emphysema severe and chronic, and alternating with scattered patches of partial collapse, in which the alveoli usually contain a coagulated exudate. No bronchiolitis. Pulmonary arteries well developed.

\section{Discussion}

Pulmonary atresia is an uncommon defect, Abbott (1936) finding 40 examples in 1000 confirmed cases of congenital morbus cordis. We have examined the necropsy reports of the London Hospital, covering a period of 31 years, and found 355 cases of congenital morbus cordis, other than those showing patent foramen ovale alone; among these were 16 cases of pulmonary atresia. Two main types are described, those in which the interventricular septum is closed and the pulmonary circulation is maintained by way of a patent foramen ovale, a dextroposed aorta, and a patent ductus arteriosus; and those in which the interventricular septum is perforate. The prognosis is different, being far worse in the first type with an average duration of life of 3 months and a maximum of 6 months, against an average of 3.4 years with a maximum of 13 years in the second type, as given in Abbott's (1928) series of 31 cases. Harrison (1929) 
comments on the relatively favourable prognosis where the interventricular septum is patent, and cases, aged 33 and 30, have been reported by East and Barnard (1938), and Bach (1928), respectively. The collateral circulation in this type has been fully discussed by Harrison (1929), who emphasized the importance of the bronchial arteries in maintaining it when the ductus arteriosus was closed, and gave references. This was recently noted in two cases by East and Barnard (1938), and it was a feature in our case, where incidentally the aorta sprang normally from the left ventricle and was not dextroposed.

The bronchial arteries normally arise from the aorta or intercostal arteries and supply the lung tissue (Gray's Anatomy, 26th edition, 1935). They vary in number from one to three for each lung, generally with two on the left and one on the right, and with an anastomosis between these vessels and the branches of the pulmonary artery. The compensatory circulation may also be maintained by a patent ductus arteriosus, by the mediastinal, œsophageal, and other branches of the aorta, or by anomalous vessels arising from the subclavian and thyroidea ima arteries (Abbott, 1932).

The diagnosis of pulmonary atresia cannot always be made during life as the syndrome of gross cyanosis and clubbing of the fingers, with the caur en sabot of right ventricular enlargement resembles closely the commoner form of Fallot's tetralogy where there is stenosis, not atresia. If a harsh systolic murmur and thrill in the pulmonary area are added the distinction seems impossible. But sometimes, where the septal defect is large, as in our case, the murmur is slight and the thrill absent; this should suggest the diagnosis.

Cerebral manifestations in pulmonary atresia and stenosis are well recognized. They have been attributed either to paradoxical embolism, or to cerebral thrombosis associated with the polycythæmia. We here record hemiplegia and epileptiform attacks which were shown at necropsy to be due to cerebral thrombosis. Their transient nature may be explained by the absence of softening of the brain although there was such extreme distension and thrombosis of the cerebral veins (see Fig. 5).

We are glad to acknowledge the kindness of Professor H. M. Turnbull, F.R.S., and Dr. W. W. Woods of the Bernhard Baron Institute of Pathology in furnishing us with the detailed necropsy report, and with Fig. 5. Professor Turnbull has kindly permitted reference to past records.

Dr. A. E. Clark Kennedy, Physician to the London Hospital, was good enough to allow us to publish this case which was admitted under his care, and Dr. William Evans has helped us in the Cardiac Department.

\section{REFERENCES}

Abbott, M. E. (1928). Blumer's Bedside Diagnosis, Vol. II. (1932). Nelson's Loose Leaf Medicine, 4, 207-321. (1936). Atlas of Congenital Cardiac Disease, New York. Bach, F. (1928). Lancet, 1, 1009.

Corner, B., and Perry, B. (1942). Brit. Heart. J., 4, 120.

East, T., and Barnard, W. G. (1938). Ibid., 834.

Harrison, W. F. (1929). Amer. Heart J., 5, 212. 